\title{
Use of a Pressure Guidewire to Assess Pulmonary Artery Band Adequacy in the Hybrid Stage I Procedure for High-risk Neonates with Hypoplastic Left Heart Syndrome and Variants
}

\author{
Jeffrey D. Zampi, MD, ${ }^{\star}$ Jennifer C. Hirsch, MD, MS, ${ }^{\dagger}$ Bryan H. Goldstein, $M D,{ }^{\ddagger}$ and \\ Aimee K. Armstrong, MD* \\ ${ }^{*}$ Division of Pediatric Cardiology, Department of Pediatrics, University of Michigan, Ann Arbor, Mich, ${ }^{\dagger}$ Division of \\ Pediatric Cardiac Surgery, Department of Surgery, University of Michigan, Ann Arbor, Mich., ${ }^{\ddagger}$ The Heart Institute, \\ Cincinnati Children's Hospital Medical Center, Cincinnati, Ohio, USA
}

\begin{abstract}
A B S T R A C T
Objective. The hybrid stage I procedure is an alternative palliative strategy for patients with hypoplastic left heart syndrome who traditionally have undergone the Norwood operation. At our institution, the hybrid stage I procedure is employed only for patients with high operative risk. Our objective was to describe our use of a pressure guidewire during the hybrid stage I procedure to assess quantitatively pulmonary artery band adequacy.

Design. After reviewing the charts on all high-risk patients who underwent a hybrid stage I procedure at our institution, we compared two groups of patients: those who underwent the standard hybrid stage I palliation (standard cohort) and those with pressure wire-facilitated assessment of distal branch pulmonary artery pressure (pressure wire cohort) to evaluate the impact of pressure guidewire use on procedural risk, radiation time, patient outcomes, and need for reoperation for pulmonary artery band adjustment.

Results. The pressure guidewire was used in 8 of 14 patients at the time of hybrid stage I procedure and was successful and without complication in all attempts. In the standard cohort, $67 \%$ of patients needed reoperation for pulmonary artery band adjustment, compared to $12.5 \%$ of patients in the pressure wire cohort $(P=.09)$. Procedure time, radiation exposure, and survival to hospital discharge were not different between groups.

Conclusions. This novel use of a pressure guidewire to assess quantitatively pulmonary artery band adequacy at the time of placement is feasible, safe and may decrease the need for reoperation for pulmonary artery band adjustment.
\end{abstract}

Key Words. Congenital Heart Disease; Cardiac Catheterization; Hybrid; Hypoplastic Left Heart Syndrome

\section{Introduction}

$\mathrm{P}$ atients with hypoplastic left heart syndrome (HLHS) and HLHS variants have traditionally been palliated to Fontan physiology via a series of staged cardiac surgeries, the first of which is the Norwood procedure. Recently, a hybrid strategy combining transcatheter and surgical techniques has been developed as an alternative to the Norwood operation. ${ }^{1-6}$ This less

All work was performed at the University of Michigan, Ann Arbor, MI.

Institutional Review Board status: Approved.

Financial Support: None. invasive procedure that does not require cardiopulmonary bypass may decrease perioperative and postoperative morbidity and mortality. ${ }^{1-6}$ While the hybrid stage I procedure may be performed as an alternative to the Norwood operation for standard risk patients, our institution has adopted a strategy of utilizing hybrid stage I palliation only for patients with high operative risk, defined as those with two or more risk factors for poor outcome after the Norwood operation., $1,3,4,7-10$ These high operative risk factors include low birth weight (less than $2.5 \mathrm{~kg}$ ), prematurity, an intact or highly restrictive atrial septum (IAS), severe tricuspid regurgitation, severely depressed right 
ventricular function, severe ascending aortic hypoplasia (less than $2 \mathrm{~mm}$ ), severe noncardiac medical or genetic abnormalities, including renal dysfunction and intracranial hemorrhage/neurologic injury, or postnatal cardiovascular collapse. . $^{1,7-10}$ The hybrid stage I approach may help to lessen the risk to this subset of critically ill newborns, but it presents new challenges to operators and clinicians who take care of these patients in the perioperative period.

Placement of bilateral branch pulmonary artery (PA) bands, to balance the pulmonary and systemic circulations, is one such challenge of the hybrid stage I procedure that is particularly difficult in a high-risk HLHS and HLHS variant population. ${ }^{2,5}$ The techniques previously described to determine adequate PA banding in the operating room include a standardized predetermined external or internal diameter of the bands, ${ }^{6,11}$ angiographic assessment of the pulmonary arteries, ${ }^{1}$ response of the systemic blood pressure, ${ }^{1,3}$ oxygen saturation change, ${ }^{1,3,11}$ and surgeon judgment based on patient size. ${ }^{3}$ Postoperatively, assessing the amount of restriction by the PA bands is difficult and usually reliant on transthoracic echocardiogram and clinical assessment. ${ }^{12,13}$

In response to the late finding of PA hypertension in several of our early high-risk patients who had undergone initial palliation with the hybrid stage I procedure, we modified our hybrid protocol to include measurement of the distal branch $\mathrm{PA}$ pressures at the time of band placement, using a pressure guidewire. We hypothesized that intraprocedure branch PA pressure measurements would aid in the determination of PA band adequacy, thereby reducing the need for subsequent PA band adjustments and would improve the long-term outcome for this high-risk singleventricle population. We describe our technique of using a pressure guidewire during the hybrid stage I procedure to assess quantitatively the decrease in distal PA pressure at the time of PA band placement. To our knowledge, this is the first published description of the use of a pressure guidewire for this purpose. We also describe our use of the pressure guidewire at subsequent cardiac catheterizations to assess PA pressures.

\section{Methods}

After obtaining approval from our institutional review board, we reviewed the medical records and cardiac catheterization reports for all patients who have undergone hybrid stage I palliation with placement of branch PA bands in the hybrid cardiac catheterization laboratory at the University of Michigan between 2009 and 2011. In this descriptive study, we reported outcomes following hybrid stage I palliation in high-risk operative candidates with HLHS and HLHS variant anatomy. We compared patients who underwent hybrid stage I palliation prior to our use of the pressure guidewire during the initial procedure (standard cohort) to those who underwent the procedure with use of the pressure guidewire (pressure wire cohort). Important outcome variables included procedural characteristics (procedure duration, radiation exposure, complications, PA band adjustments made during the procedure), postoperative variables (need for reoperation for PA band adjustment, hospital length of stay), and key clinical outcomes (successful comprehensive stage II completion and survival). We also described our experience using a pressure guidewire at subsequent cardiac catheterizations to assess PA band adequacy and described the changes that occur in PA pressures and pulsatility over time. Pulsatility of pressure tracings was defined as the difference between the systolic and diastolic pressures.

Data are presented as percentages or means with standard deviations. To compare groups, Fisher's exact test was used for dichotomous variables while Wilcoxon sum rank test was used for continuous variables.

\section{Technical Description: Pressure Guidewire Use at Hybrid Stage I Procedure}

A median sternotomy was performed, and the bilateral branch PAs were exposed. In the setting of an intact or highly restrictive atrial septum, patients underwent peratrial atrial septal stent placement under transesophageal echocardiographic and fluoroscopic guidance. In the presence of a mildly or moderately restrictive atrial septal defect with a mean gradient by echocardiogram of $\geq 8 \mathrm{~mm} \mathrm{Hg}$, a percutaneous Rashkind balloon atrial septostomy (BAS) was performed prior to the hybrid stage I procedure. Patients with a mean gradient across the atrial septal defect of $<8 \mathrm{~mm} \mathrm{Hg}$ underwent a Rashkind BAS prior to discharge from the hospital. At the time of the hybrid procedure, PA bands were created using either a $3.0-\mathrm{mm}$ (for patients $\leq$ $2.5 \mathrm{~kg}$ ) or $3.5-\mathrm{mm}$ (for patients $>2.5 \mathrm{~kg}$ ) nonstretch Gore-Tex (Gore Medical, Flagstaff, AZ, USA) tube graft, which was cut to a width of $2 \mathrm{~mm}$. The bands were then fashioned around both the left and right PAs, with simultaneous measurement of postductal oxygen saturation and arterial blood pressure. 
A purse string suture was placed in the main PA and a 6 French sheath (Arrow International, Inc., Reading, PA, USA) was inserted through a stab incision. A 4 French JB1 catheter with a 0.014-inch Primewire Prestige coronary guidewire (Volcano Corporation, San Diego, CA, USA) was advanced through the sheath and across the ductus arteriosus into the descending aorta. The guidewire has a micromanometer pressure sensor $3 \mathrm{~cm}$ from the tip of the wire. With the wire extending at least $3 \mathrm{~cm}$ out of the catheter, it was equalized to the descending aortic pressure. After pulling the catheter and wire back into the sheath, the surgeon directed the sheath toward either the right or left PA. The wire was advanced under fluoroscopic guidance $>3 \mathrm{~cm}$ past the PA band to measure the pressure, and the process was repeated in the contralateral PA. After gaining some experience with the technique, we have deemed PA bands to be adequate, if the mean distal PA pressure is between 17 and $20 \mathrm{~mm} \mathrm{Hg}$ with some pulsatility. The PA bands were adjusted until the distal PA pressure meets these criteria. Bilateral PA pressures were remeasured after each PA band adjustment. Figures 1 and 2 are examples of how tracings obtained from the pressure guidewire were used to make band adjustments during the hybrid procedure. Next, stenting of the ductus arteriosus was performed via the 6 French

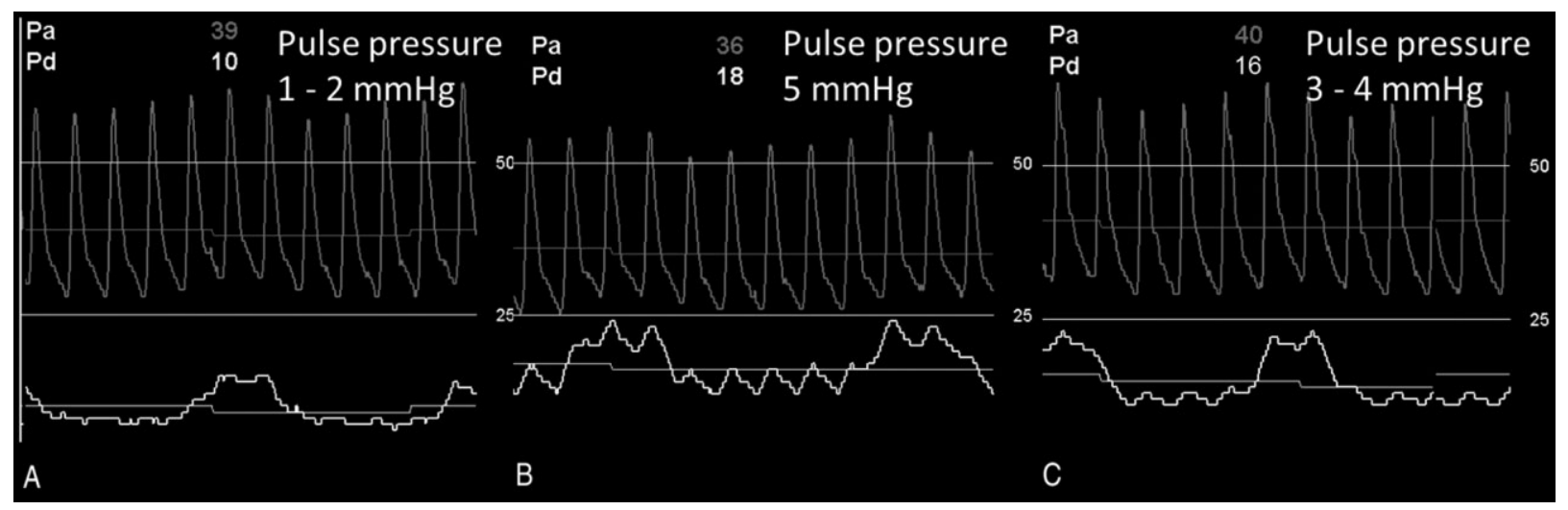

Figure 1. Pulmonary artery band adjustment based on pressure guidewire data. Figure 1 shows how a right PA band was adjusted based on pressure guidewire data. After initial band placement $(A)$, there was low mean distal PA pressure and low pulsatility. The right PA band was loosened, and repeat pressure tracing showed higher mean distal PA pressure with increased pulsatility (B). Finally, the band was slightly loosened to obtain mean distal PA pressure and pulsatility within a desired range $(\mathrm{C})$. Legend: Pa (light grey, high spiking tracing) = mean MPA pressure; Pd (dark grey, lower, more sinusoidal tracing $)$ = mean distal PA pressure; pulse pressure = pulsatility. PA, pulmonary artery; MPA, main pulmonary artery.

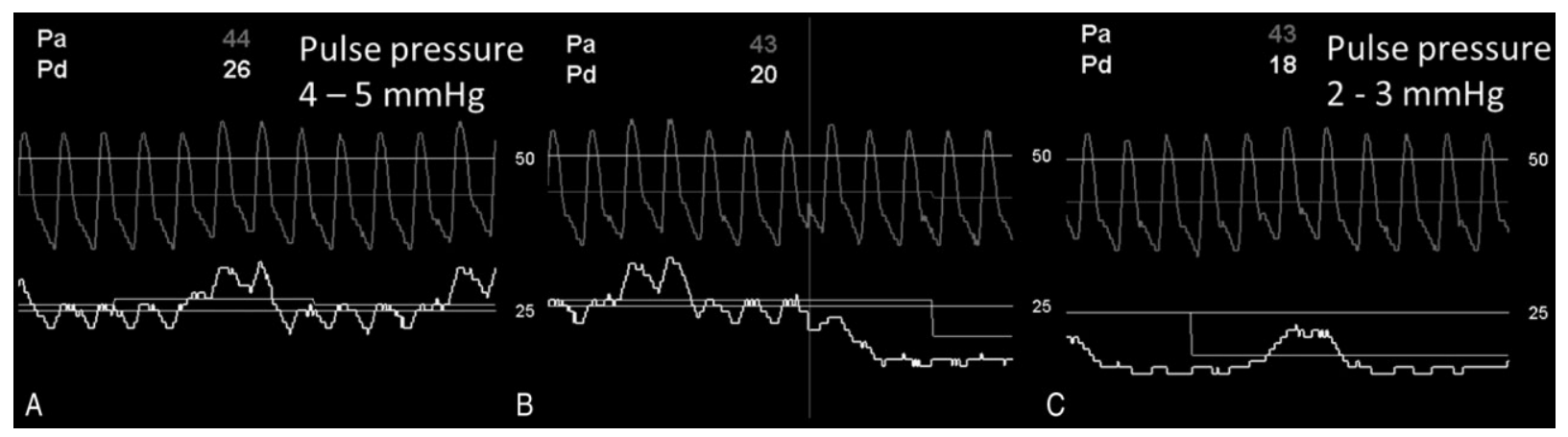

Figure 2. Pulmonary artery band adjustment based on pressure guidewire data. Figure 2 depicts right PA band adjustment using pressure guidewire data in a different patient. After initial band placement (A), there was high mean distal PA pressure and wide pulsatility, which was clinically associated with a descending aortic oxygen saturation $>90 \%$. As the band was tightened, there was a transition (vertical grey line) from a high mean distal PA pressure and wide pulsatility to a lower mean pressure and pulsatility (B), resulting in a mean distal PA pressure and pulsatility within a desired range (C). The final band position was clinically associated with an oxygen saturation of $\sim 70-75 \%$. Legend: Pa (light grey, high spiking tracing) $=$ mean MPA pressure; Pd (dark grey, lower, more sinusoidal tracing) = mean distal PA pressure; pulse pressure = pulsatility. PA, pulmonary artery; MPA, main pulmonary artery. 
sheath using an ev3 Protege EverFlex selfexpanding stent (Coviden Corporation, Plymouth, MN, USA).

\section{Technical Description: Pressure Guidewire Use at Subsequent Cardiac Catheterizations}

When patients returned to the cardiac catheterization laboratory for percutaneous diagnostic or interventional catheterizations, prior to the comprehensive stage II procedure, measurement of PA pressures was performed either by pulmonary venous wedge pressure measurement or by direct measurement using a pressure guidewire. In some cases, both methods were used. When using the pressure guidewire, access to the main $\mathrm{PA}$ was obtained in the standard fashion via a right heart catheter course. Typically, a 4 French JB1 catheter was used, first to direct the pressure guidewire across the ductus arteriosus, in order to equalize the pressure guidewire to systemic pressure, and then to direct the pressure guidewire into the branch PAs for direct pressure measurement.

\section{Results}

Fourteen patients at our institution underwent a hybrid stage I procedure in the hybrid pediatric cardiac catheterization laboratory between January 2009 and October 2011. All met two or more high-risk criteria for the Norwood procedure (Table 1). Six patients, all in our early experience, had PA bands placed without the use of the pressure guidewire and reflect the standard cohort. The pressure guidewire was used in the remaining eight patients and reflects the pressure wire cohort. Of the 12 patients who underwent at least one cardiac catheterization following the hybrid stage I procedure, 10 had branch PA pressures assessed using the pressure guidewire. The other two had PA pressure assessment by pulmonary venous wedge pressure alone.

Of the six patients in the standard cohort, three patients underwent band adjustments during the hybrid procedure; one based on hypoxemia, 1 based on angiographic and transesophageal echocardiographic findings, and one based on hypotension. Subsequent to the hybrid stage I procedure, three of these initial six patients required an additional surgery for PA band adjustment and a fourth patient was scheduled to undergo band adjustment but died prior to the operation (Table 2). The first patient underwent PA band tightening due to pulmonary overcirculation with hypotension, elevated oxygen satura- tions, and lactic acidosis. The next two had their PA bands loosened due to hypoxemia; one was found by magnetic resonance imaging (MRI) to have $20 \%$ of pulmonary blood flow to the right lung with a $\mathrm{Qp}$ : Qs of $0.3: 1$ and the other had hypoxemia while trialing off extracorporeal membrane oxygenation support. The fourth patient had clinical evidence of systemic hypoperfusion and died secondary to complications from necrotizing enterocolitis prior to PA band adjustment.

Of the eight patients in the pressure wire cohort, four underwent PA band adjustment during the hybrid procedure based on the results of the pressure guidewire data. In this group, only one of the eight patients required a subsequent reoperation to have a PA band adjusted (band loosened due to hypoxemia). Thus, the reoperation rate decreased from $67 \%$ to $13 \%$ ( $P$ value .09 ).

The procedure time, radiation exposure, hospital length of stay, duration of mechanical ventilation, and oxygen saturation at hospital discharge were not significantly different between the two groups. While not statistically significant, patients in the pressure wire cohort required inotropic medications for nearly half the number of days compared with the standard cohort. There were no complications related to pressure wire use in any of the patients. Overall survival for all patients undergoing a hybrid stage I procedure was $71 \%$ with a median follow-up time of 271 days (interquartile range [IQR] 162 to 707 days). Overall survival was $67 \%$ in the standard cohort (median follow-up 788 days, IQR 303 to 924 days) and $75 \%$ in the pressure wire cohort (median follow-up 227 days, IQR 181 to 336 days). Survival to hospital discharge was $79 \%$ for the entire cohort, $67 \%$ for the standard cohort, and $86 \%$ for the pressure wire cohort.

In general, PA pressures at follow-up catheterization were slightly lower than the pressures at the time of the hybrid stage I procedure (Figures 3 and 4, Table 3). Pulsatility of the distal branch PA did not change significantly at follow-up catheterization (Table 3). The changes in RPA and LPA pressures over time, whether or not pressure was measured during the hybrid stage I procedure, are shown in Figures 3 and 4. Only patients with more than one assessment of PA pressure were included in these figures. All attempts to measure distal PA pressures using the pressure guidewire during subsequent catheterizations were successful with no complications related to pressure wire use. 
Table 1. Patient Description

\begin{tabular}{|c|c|c|c|c|c|c|}
\hline \multirow[b]{2}{*}{ Patient } & \multirow[b]{2}{*}{ Diagnosis } & \multicolumn{2}{|c|}{ Risk Factors } & \multirow{2}{*}{$\begin{array}{l}\text { Hybrid } \\
\text { Performed }\end{array}$} & \multirow[b]{2}{*}{ Cohort } & \multirow[b]{2}{*}{ Current Status } \\
\hline & & Number & Description & & & \\
\hline 1 & HLHS (MS/AS) & 2 & $\begin{array}{l}\text { Restrictive atrial septum (s/p } \\
\text { fetal septoplasty), Turner's } \\
\text { syndrome }\end{array}$ & $\begin{array}{l}\text { ASS, PAB } \\
\text { (subsequent } \\
\text { DAS) }\end{array}$ & $S$ & $\begin{array}{l}\text { Alive; initial Norwood/BT; } \\
\text { currently, hemi-Fontan }\end{array}$ \\
\hline 2 & HLHS (MA/AS) & 2 & $\begin{array}{l}\text { Prematurity ( } 33 \text { weeks), low } \\
\text { birth weight }(1.87 \mathrm{~kg})\end{array}$ & DAS, PAB & $\mathrm{S}$ & $\begin{array}{l}\text { Alive; failed comprehensive } \\
\text { stage II; subsequent } \\
\text { successful hemi-Fontan }\end{array}$ \\
\hline 3 & HLHS (MS/AA) & 4 & $\begin{array}{l}\text { Intact atrial septum (s/p fetal } \\
\text { septoplasty), LV sinusoids, } \\
\text { prematurity ( } 36 \text { weeks), } \\
\text { low birth weight }(2.22 \mathrm{~kg})\end{array}$ & ASS, DAS, PAB & $S$ & Deceased \\
\hline 4 & HLHS (MA/AA) & 2 & $\begin{array}{l}\text { Restrictive atrial septum (s/p } \\
\text { fetal septoplasty), LV } \\
\text { sinusoids }\end{array}$ & ASS, DAS, PAB & $\mathrm{S}$ & $\begin{array}{l}\text { Alive; currently, hemi-Fontan } \\
\text { after failed hemi-Fontan }\end{array}$ \\
\hline 5 & HLHS (MS/AA) & 3 & $\begin{array}{l}\text { LV sinusoids, prematurity } \\
\text { (34 weeks), renal disease }\end{array}$ & DAS, PAB & $S$ & $\begin{array}{l}\text { Alive; successful } \\
\text { comprehensive stage II }\end{array}$ \\
\hline 6 & IAA/VSD, HLV & 2 & $\begin{array}{l}\text { Clinical DiGeorge syndrome, } \\
\text { renal failure }\end{array}$ & DAS, PAB & PW & Deceased \\
\hline 7 & Shone's Complex & 2 & $\begin{array}{l}\text { Severely depressed ventricular } \\
\text { function, postnatal arrest } \\
\text { requiring ECMO }\end{array}$ & $\begin{array}{l}\text { PAB } \\
\text { (Subsequent } \\
\text { DAS) }\end{array}$ & $\mathrm{S}$ & Deceased \\
\hline 8 & Shone's Complex & 2 & $\begin{array}{l}\text { Prematurity ( } 36 \text { weeks), low } \\
\text { birth weight }(2.03 \mathrm{~kg})\end{array}$ & DAS, PAB & PW & $\begin{array}{l}\text { Alive; successful } \\
\text { Norwood/Rastelli }\end{array}$ \\
\hline 9 & Critical AS & 2 & $\begin{array}{l}\text { Critical AS with severely } \\
\text { depressed LV function and } \\
\text { LV endofibroeleastosis, } \\
\text { moderate aortic and mitral } \\
\text { regurgitation }\end{array}$ & AS, PAB & PW & $\begin{array}{l}\text { Alive; successful } \\
\text { comprehensive stage II }\end{array}$ \\
\hline 10 & HLHS (MS/AA) & 2 & $\begin{array}{l}\text { Turner's syndrome, low birth } \\
\text { weight }(2.55 \mathrm{~kg})\end{array}$ & AS, DAS, PAB & PW & $\begin{array}{l}\text { Alive; failed comprehensive } \\
\text { stage II. Currently } \\
\text { Norwood with central } \\
\text { shunt }\end{array}$ \\
\hline 11 & Critical AS & 2 & $\begin{array}{l}\text { Critical AS with severely } \\
\text { depressed LV function and } \\
\text { LV endofibroeleastosis, LV } \\
\text { sinusoids }\end{array}$ & DAS, PAB & PW & $\begin{array}{l}\text { Alive; successful } \\
\text { comprehensive stage II }\end{array}$ \\
\hline 12 & Critical AS & 4 & $\begin{array}{l}\text { Critical AS with severely } \\
\text { depressed LV function and } \\
\text { LV endofibroeleastosis, } \\
\text { multiple genetic deletions, } \\
\text { prematurity ( } 36 \text { weeks), } \\
\text { low birth weight }(2.35 \mathrm{~kg})\end{array}$ & DAS, PAB & PW & Deceased \\
\hline 13 & HLHS (MA/AA) & 4 & $\begin{array}{l}\text { Prematurity ( } 33 \text { weeks), low } \\
\text { birth weight }(1.76 \mathrm{~kg}) \\
\text { postnatal arrest, renal failure }\end{array}$ & PAB & PW & Alive; successful Norwood \\
\hline 14 & HLHS (MS/AA) & 2 & $\begin{array}{l}\text { Low birth weight }(1.6 \mathrm{~kg}) \\
\text { severely hypoplastic } \\
\text { ascending aorta }(1.4 \mathrm{~mm})\end{array}$ & $A S, P A B, D A B$ & PW & $\begin{array}{l}\text { Alive; successful Norwood } \\
\text { operation (performed at } 2 \\
\text { months of age due to } \\
\text { retrograde coarct) }\end{array}$ \\
\hline
\end{tabular}

AS, atrial septostomy; ASS, atrial septal stent; PAB, pulmonary artery band placement; DAS, ductus arteriosus stent placement; S, standard cohort; PW, pressure wire cohort; HLHS, hypoplastic left heart syndrome; MS, mitral stenosis; MA, mitral atresia; AS, aortic stenosis; AA, aortic atresia; IAA, interrupted aortic arch; VSD, ventricular septal defect; HLV, hypoplastic left ventricle; LV, left ventricle; ECMO, extracorporeal membrane oxygenation.

There were four patients who had assessment of their PA pressures using both the pressure guidewire and pulmonary vein wedge pressure during the same cardiac catheterization (Table 4). In general, the mean pressures correlated well with the exception of those in patient 11, who had discrepant pulmonary vein wedge pressures, depending on which pulmonary was assessed.

\section{Discussion}

The hybrid stage I procedure for HLHS and HLHS variants is a reasonable preliminary alternative to standard surgery, especially in patients at high operative risk. ${ }^{1,2,-6,9,11}$ In January 2009, we began performing the hybrid stage I procedure for patients with two or more operative risk factors. We found that there is a learning curve for 
Table 2. Patient Outcomes before and after Pressure Guidewire Use at Time of Pulmonary Artery Band Placement ${ }^{a}$

\begin{tabular}{|c|c|c|}
\hline & Standard Cohort & Pressure Wire Cohort \\
\hline Number of patients & 6 & 8 \\
\hline \multicolumn{3}{|l|}{ Final mean PA pressures postbanding, median (range) in $\mathrm{mm} \mathrm{Hg}$} \\
\hline Right & $\mathrm{n} / \mathrm{a}$ & $19(14-29)$ \\
\hline Left & $\mathrm{n} / \mathrm{a}$ & $20.5(13-29)$ \\
\hline \multicolumn{3}{|l|}{ PA band adjustments, number of patients (\%) } \\
\hline During hybrid procedure & $3(50)$ & $4^{\mathrm{b}}(50)$ \\
\hline After hybrid procedure (additional surgery) & $4^{c}(67)$ & $1(13)$ \\
\hline Complications due to pressure wire use & $\mathrm{n} / \mathrm{a}$ & None \\
\hline Fluoroscopy time (minutes) ${ }^{\mathrm{d}, \mathrm{e}}$ mean (SD) & $18.9(10.4)$ & $18.4(13.2)$ \\
\hline Procedure time (minutes) $)^{d, e, f}$ mean (SD) & $166.7(56.9)$ & $165.1(64.9)$ \\
\hline Hospital Length of stay (days after initial hybrid procedure), mean (SD) & $26.5(12.1)$ & $41.5(27.2)^{i}$ \\
\hline Mechanical ventilator support (days after hybrid procedure), mean (SD) & $15.8(12.1)$ & $13.4(22.4)^{\mathrm{j}}$ \\
\hline Inotropic support (days after hybrid procedure) ${ }^{g}$ mean (SD) & $8.5(5.8)$ & $4.3(2.5)$ \\
\hline Oxygen saturation at discharge (on room air), mean (SD) & $77-85(6.4,8.4)$ & $74-84(6.6,8.8)$ \\
\hline Survival to hospital discharge, $\mathrm{n}(\%)$ & $4(67)$ & $6(86)^{\mathrm{k}}$ \\
\hline Overall survival $\mathrm{n}(\%)$ & $4(67)$ & $6(75)$ \\
\hline Successful comprehensive stage $2, \mathrm{n}(\%)$ & $1(17)$ & $2(25)$ \\
\hline Required Norwood procedure prior to hemi-Fontan, n (\%) & $1(17)$ & $1(13)$ \\
\hline Failed initial attempt at Comprehensive stage II repair, $\mathrm{n}(\%)$ & $2(33)$ & $1(13)$ \\
\hline Two ventricular repair, n (\%) & $0(0)$ & 1 (13) \\
\hline Awaiting comprehensive stage II, n (\%) & $0(0)$ & $0(0)$ \\
\hline Awaiting completion of hybrid stage 1 procedure, $\mathrm{n}(\%)$ & $0(0)$ & $1(13)$ \\
\hline
\end{tabular}

aStatistical analysis (either Fisher's exact test or Wilcoxon rank-sum test) was performed and revealed no statistical differences between the groups for any variable on this table.

${ }^{b}$ All adjustments made due to data obtained from pressure wire.

'One patient was scheduled to have band adjustment but died prior to procedure.

dOnly includes patients who have had all parts of hybrid completed, excludes balloon atrial septostomy if done as separate procedure.

elf hybrid performed as two separate procedures, times of procedures and fluoroscopy added together.

fProcedure time = incision to surgical bandage.

IInotropic support includes any medication given to support cardiac function and blood pressure, including dopamine, epinephrine, vasopressin, calcium chloride infusion.

${ }^{\text {h} A l l}$ deaths occurred prior to attempted comprehensive stage II repair.

iTwo patients in the pressure wire cohort had prolonged length of hospital stay related to comorbid medical conditions. If these two outliers are excluded from length of stay analysis, the mean hospital stay for the pressure wire cohort is 24.5 days.

'Excludes a patient who was tracheostomy- and ventilator-dependent due to airway abnormalities related to a genetic defect.

kOne patient alive but has not been discharged from the hospital yet.

$\mathrm{PA}$, pulmonary artery; SD, standard deviation.

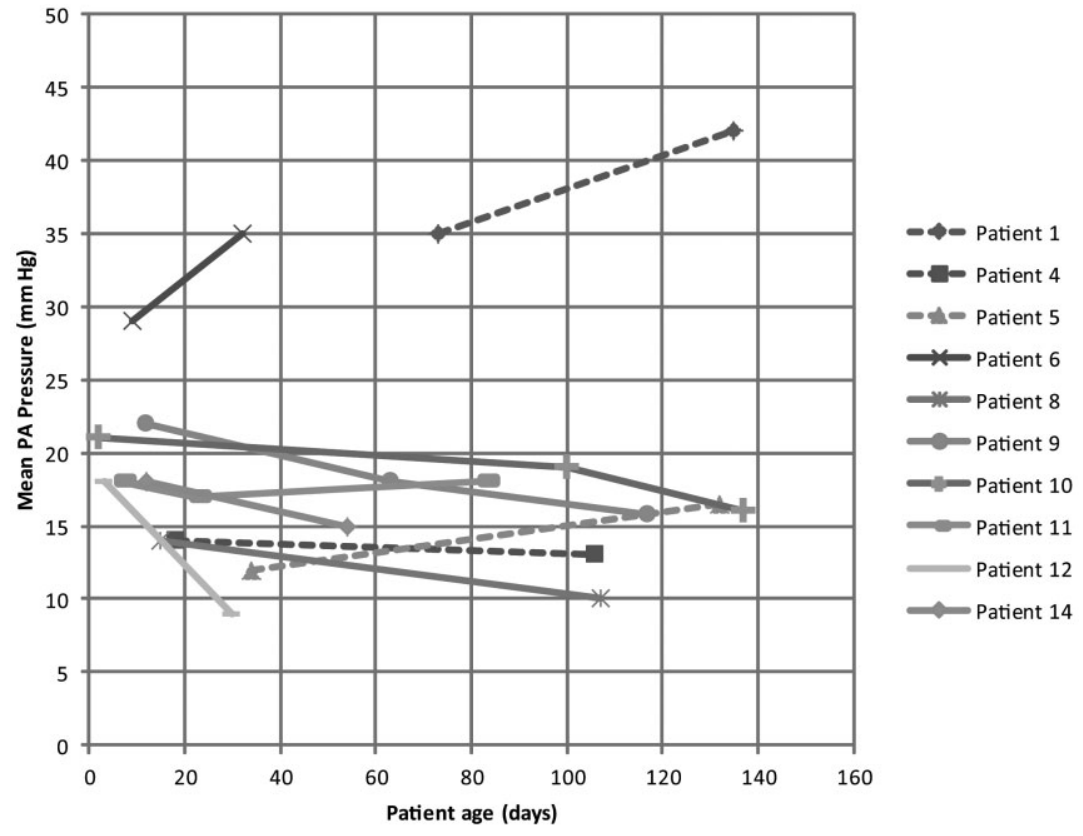

Figure 3. Right pulmonary artery (PA) pressure change with time. Legend: dotted lines, standard cohort patient; solid lines, pressure wire cohort patients. 


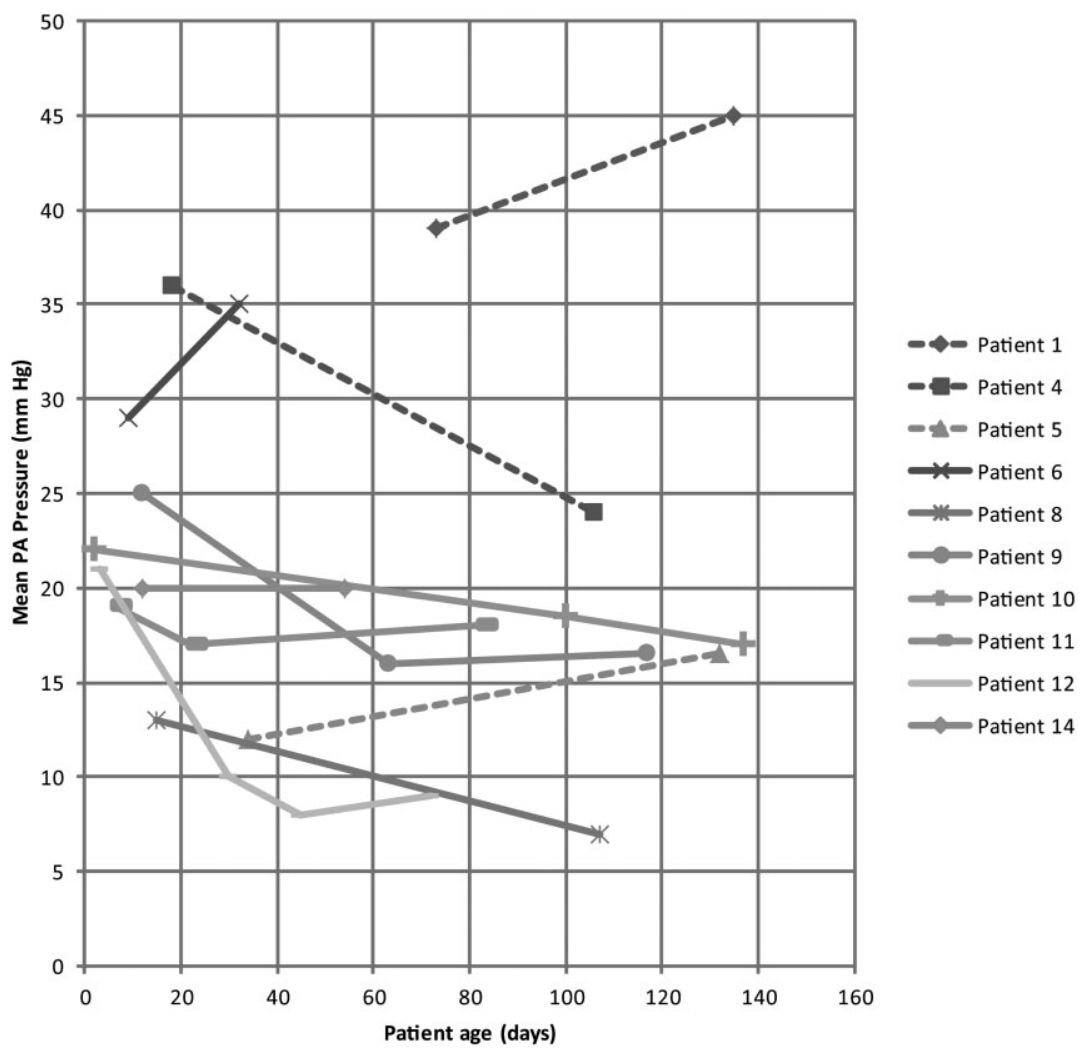

Figure 4. Left pulmonary artery (PA) pressure change with time. Legend: dotted lines, standard cohort patient; solid lines, pressure wire cohort patients.

Table 3. Mean Pulmonary Artery Pressure and Pulsatility at the Time of Hybrid Stage I Procedure and Over Time*

\begin{tabular}{lllll}
\hline & \multicolumn{2}{l}{$\begin{array}{l}\text { RPA } \\
\text { Mean (Pulse Pressure) } \mathrm{mm} \mathrm{Hg}\end{array}$} & & \multicolumn{2}{l}{ LPA } \\
\cline { 2 - 5 } Pean (Pulse Pressure) mm Hg
\end{tabular}

*Only includes patients whose PA pressures were measured with the pressure guidewire at the time of the hybrid stage I procedure.

tAll pressures obtained with hybrid physiology (i.e., before next stage or surgery).

$\ddagger$ Pressure obtained from pulmonary venous wedge measurement.

PA, pulmonary artery; RPA, right pulmonary artery; LPA, left pulmonary artery; F/U, follow-up. 
Table 4. Comparison of Mean Pulmonary Artery Pressure Assessment Using Pressure Wire and Pulmonary Venous Wedge Assessment*

\begin{tabular}{|c|c|c|c|c|}
\hline \multirow[b]{2}{*}{ Patient } & \multicolumn{2}{|c|}{ RPA Mean Pressure $(\mathrm{mm} \mathrm{Hg})$} & \multicolumn{2}{|c|}{ LPA Mean Pressure $(\mathrm{mm} \mathrm{Hg})$} \\
\hline & Pressure Wire & Pulmonary Vein Wedge & Pressure Wire & Pulmonary Vein Wedge \\
\hline 5 & 18 & 15 & 17 & 16 \\
\hline 9 & 18 & 18 & 16 & 18 \\
\hline 10 & 21 & 17 & 20 & 17 \\
\hline 11 & 18 & 12 to 16 & 18 & 10 to 16 \\
\hline
\end{tabular}

*Pressures obtained during same catheterizations using both pressure guidewire and pulmonary venous wedge pressure.

RPA, right pulmonary artery; LPA, left pulmonary artery.

performing this procedure, particularly for the appropriate tightness of the PA bands. High-risk patients with HLHS and HLHS variant anatomy, especially those with IAS, can have intrinsic abnormalities in the pulmonary vascular bed. ${ }^{14,15}$ This inherent pulmonary vascular pathology is associated with elevated pulmonary vascular resistance, which makes the placement of adequate PA bands even more challenging. PA bands that are too loose may result in pulmonary overcirculation and systemic hypoperfusion, placing the patient at risk for a host of postoperative complications, including lactic acidosis and necrotizing enterocolitis. Over a period of months, loose bands may also result in sustained PA hypertension and the development of further pulmonary vascular changes, which may limit candidacy for future staged palliation. On the other hand, bands that are too tight may cause pulmonary hypoperfusion and hypoxemia, especially with rapid somatic growth in the postoperative period. A tight PA band may lead to anatomic PA stenosis that can be difficult to repair surgically and especially problematic for the long-term outcome in a singleventricle patient.

In our early experience, assessing PA band adequacy by angiography was not sufficient, as four of the six patients in the standard cohort needed reoperation for PA band adjustment. To date, a quantitative assessment of PA band adequacy using angiography has not been shown to predict PA pressure prior to comprehensive stage II repair. Echocardiography, including transesophageal echocardiography, is often limited by inadequate alignment of the Doppler signal to ascertain reliable gradients across the PA bands. Judgment by the surgeon may be adequate, but it can only be acquired with significant experience in this procedure with high-risk neonates. Therefore, we sought a quantitative measure of PA pressure at the time of PA band placement that could be used to reduce the need for reoperation and that eventually might be correlated with PA pressure at the time of the comprehensive stage II operation.

The use of the pressure guidewire to measure PA pressures at the time of PA band placement served as this quantitative measure with the opportunity to obtain serial measurements at subsequent catheterizations to observe PA pressure change over time. We have found that use of a pressure guidewire in high-risk patients with HLHS and HLHS variant anatomy is safe and feasible with no increase in radiation exposure or duration of the procedure. Direct PA pressure assessment allows for real-time adjustment of the bands, and it may help to prevent the need for reoperation for PA band adjustments as our rate of reoperation decreased from $67 \%$ to $13 \%$ ( $P$ value .09) following the introduction of direct PA pressure measurement during the hybrid stage I procedure.

Our data suggest that mean PA pressures stay fairly constant or fall slightly over the first 4-6 months of life in this cohort of hybrid stage I palliated high-risk HLHS and HLHS variants patients. With our first several patients, we had anticipated that the patients would "grow into" the PA bands and, therefore, placed them loosely. We found, however, that the distal PA pressures stay relatively constant or decrease slightly, unless restriction redevelops at the atrial septum, which was the case in the three patients in whom PA pressures increased over time. Our early data suggest that a mean PA pressure of approximately $17-20 \mathrm{~mm} \mathrm{Hg}$ at the time of band placement in this high-risk group of neonates will result in an adequate mean PA pressure of $14-17 \mathrm{~mm} \mathrm{Hg}$ prior to comprehensive stage II at 4-6 months of age. ${ }^{16,17}$ As we continue to use the guidewire during the hybrid stage I and subsequent catheterizations in neonates with high operative risk for standard surgical palliation, we hope to determine the ideal mean PA pressure and pulsatility that predict a successful outcome for the comprehen- 
sive stage II and the Fontan procedure. We also found that the PA mean pressure determined using the pressure wire correlated fairly well with mean pressures obtained from pulmonary venous wedge measurements and, in some circumstances, may help to avoid the inaccuracies of pulmonary venous wedge measurements from low-fidelity fluid-filled catheters and transducers as well as overwedge or underwedge recordings.

Published hospital survival of high-risk neonates undergoing a Norwood operation ranges from $42 \%$ to $75 \%,{ }^{10,18,19}$ and survival of high-risk patients undergoing a hybrid stage I procedure ranges from $65 \%$ to $75 \% ., 11$ Our hospital survival rate for the standard cohort was $67 \%$ and for the pressure wire cohort was $86 \%$. This increase did not reach statistical significance as the study population is underpowered for this analysis.

This descriptive study is limited by its retrospective nature and the small numbers of patients with limited follow-up time. Furthermore, the data were obtained during our initial experience in performing the hybrid stage I procedure. Therefore, improvement in patient outcomes may be influenced more by our cumulative experience than by the addition of a new specific technology, and lack of change in radiation exposure and procedure time also may be influenced by our experience. Lastly, our findings should not be extrapolated to standard risk neonates undergoing the hybrid stage I procedure.

\section{Conclusions}

Use of a pressure guidewire to measure mean PA pressures at the time of PA band placement during the hybrid stage I procedure in high-risk HLHS and HLHS variant patients is safe, feasible, and may help reduce the need for reoperation for PA band adjustment. By continuing to use this technology to measure mean PA pressure at the time of PA band placement, we hope to expand our knowledge of the ideal pressure and pulsatility at the time of the hybrid procedure that will achieve the best outcome for high-risk patients as they continue through the staged palliation for their singleventricle physiology.

\section{Authors' Contributions}

Jeffrey Zampi: concept/design, data collection, data analysis/interpretation, drafting article, critical revision of article, approval of article. Jennifer Hirsch: concept/ design, data analysis/interpretation, critical revision of article, approval of article. Bryan Goldstein: concept/ design, data analysis/interpretation, critical revision of article, approval of article. Aimee Armstrong: concept/ design, data collection, data analysis/interpretation, drafting article, critical revision of article, approval of article.

Corresponding Author: Jeffrey D. Zampi, MD, University of Michigan Congenital Heart Center, C.S. Mott Children's Hospital, Floor 11, Room 715Z, 1540 E. Hospital Drive, Ann Arbor, MI 48109-4204, USA. Tel: (+734) 936-3813; Fax (+734) 936-9470; E-mail: jzampi@med.umich.edu

Conflict of interest: None.

Accepted in final form: August 11, 2012.

\section{References}

1 Bacha EA, Daves S, Hardin J, et al. Single-ventricle palliation for high-risk neonates: the emergence of an alternative hybrid stage I strategy. 7 Thorac Cardiovasc Surg. 2006;131:163-171. e2.

2 Chen Q, Parry AJ. The current role of hybrid procedures in the stage 1 palliation of patients with hypoplastic left heart syndrome. Eur $\mathcal{F}$ Cardiothorac Surg. 2009;36:77-83.

3 Galantowicz M, Cheatham JP. Lessons learned from the development of a new hybrid strategy for the management of hypoplastic left heart syndrome. Pediatr Cardiol. 2005;26:190-199.

4 Galantowicz M, Cheatham JP, Phillips A, et al. Hybrid approach for hypoplastic left heart syndrome: intermediate results after the learning curve. Ann Thorac Surg. 2008;85:2063-2070; discussion $70-71$.

5 Gutgesell HP, Lim DS. Hybrid palliation in hypoplastic left heart syndrome. Curr Opin Cardiol. 2007;22:55-59.

6 Venugopal PS, Luna KP, Anderson DR, et al. Hybrid procedure as an alternative to surgical palliation of high-risk infants with hypoplastic left heart syndrome and its variants. 7 Thorac Cardiovasc Surg. 2010;139:1211-1215.

7 Ashburn DA, McCrindle BW, Tchervenkov CI, et al. Outcomes after the Norwood operation in neonates with critical aortic stenosis or aortic valve atresia. 7 Thorac Cardiovasc Surg. 2003;125:10701082.

8 Gaynor JW, Mahle WT, Cohen MI, et al. Risk factors for mortality after the Norwood procedure. Eur 7 Cardiothorac Surg. 2002;22:82-89.

9 Lim DS, Peeler BB, Matherne GP, Kron IL, Gutgesell HP. Risk-stratified approach to hybrid transcatheter-surgical palliation of hypoplastic left heart syndrome. Pediatr Cardiol. 2006;27:9195 . 
10 Stasik CN, Gelehrter S, Goldberg CS, Bove EL, Devaney EJ, Ohye RG. Current outcomes and risk factors for the Norwood procedure. 7 Thorac Cardiovasc Surg. 2006;131:412-417.

11 Pizarro C, Derby CD, Baffa JM, Murdison KA, Radtke WA. Improving the outcome of high-risk neonates with hypoplastic left heart syndrome: hybrid procedure or conventional surgical palliation? Eur 7 Cardiothorac Surg. 2008;33:613-618.

12 Fenstermaker B, Berger GE, Rowland DG, et al. Interstage echocardiographic changes in patients undergoing hybrid stage I palliation for hypoplastic left heart syndrome. $7 \mathrm{Am}$ Soc Echocardiogr. 2008;21:1222-1228.

13 Rychik J, Bush DM, Spray TL, Gaynor JW, Wernovsky G. Assessment of pulmonary/systemic blood flow ratio after first-stage palliation for hypoplastic left heart syndrome: development of a new index with the use of Doppler echocardiography. 7 Thorac Cardiovasc Surg. 2000;120:81-87.

14 Grant CA, Robertson B. Microangiography of the pulmonary arterial system in "hypoplastic left heart syndrome." Circulation. 1972;45:382-388.
15 Rychik J, Rome JJ, Collins MH, DeCampli WM, Spray TL. The hypoplastic left heart syndrome with intact atrial septum: atrial morphology, pulmonary vascular histopathology and outcome. $7 \mathrm{Am}$ Coll Cardiol. 1999;34:554-560.

16 Masuda M, Kado H, Shiokawa Y, et al. Clinical results of the staged Fontan procedure in highrisk patients. Ann Thorac Surg. 1998;65:17211725.

17 Nakanishi T. Cardiac catheterization is necessary before bidirectional Glenn and Fontan procedures in single ventricle physiology. Pediatr Cardiol. 2005;26:159-161.

18 Bove EL. Surgical treatment for hypoplastic left heart syndrome. Jpn $\mathcal{F}$ Thorac Cardiovasc Surg. 1999;47:47-56.

19 Wernovsky G, Kuijpers M, Van Rossem MC, et al. Postoperative course in the cardiac intensive care unit following the first stage of Norwood reconstruction. Cardiol Young. 2007;17:652-665. 